\title{
Drinking among medical students: a questionnaire survey
}

\author{
D J Collier, I L P Beales
}

\begin{abstract}
To assess the prevalence of drinking among medical students a questionnaire on smoking, exercise, drinking, and weight was distributed among the students available. A total of $\mathbf{2 6 0}$ replies were received from an estimated available population of 350 students (134 men and 126 women). The mean alcohol consumption obtained by a quantity-frequency measure was 20.5 units/week for male students and 14.6 units/week for female students. Retrospective diary reports showed mean (SE) consumptions of 18 (2) units/week for men $(n=134)$ and 11 (1) units/week for women $(n=126)$. Consumption among the men closely matched consumption among men matched for age in the general population. Women, however, drank more than women matched for age. Male and female medical students exceeded the suggested maximum for their sex in equal proportions. Quantity-frequency data showed that $31(23 \%)$ men drank over 35 units/week and $28(22 \%)$ women drank over 21 units/week. Of the 59 students exceeding these limits, 51 responded positively to a standard screening questionnaire for alcohol abuse. Forty students reported that they might have a drinking problem, and 138 reported that alcohol had affected their academic performance at some time; 17 of these were affected frequently. The students suggested sensible maximum consumption figures for health education. Smoking was associated with heavy drinking, especially among the women.
\end{abstract}

These results suggest that some medical students are compromising their future health and their academic performance through excessive drinking.

\section{Introduction}

Doctors have been accused of having double standards on alcohol ${ }^{1}$ because they do not have a consistent policy on safe levels of consumption ${ }^{2}$ and do not take adequate histories of drinking. ${ }^{3}$ Many doctors do not take the problem of alcohol abuse seriously enough and yet, when confronted by someone who drinks more than they do, often adopt a judgmental stance.

The incidence of cirrhosis among doctors is falling but remains above the national average and suggests that drinking is a considerable and continuing problem within the profession. ${ }^{5}$ There is a remarkable dearth of information on the impact of alcohol on medical students. In 1869, however, James Paget reported what became of medical students, presenting information on the fate of 1000 of his former pupils. ${ }^{6}$ Of 56 pupils who had "failed entirely," 10 had done so "through the continuance of the same habits of intemperance or dissipation, as had made us, even while they were students, anticipate their failure." We studied the drinking behaviour and attitudes towards drink of medical students and their perception of safe levels of drinking.

\section{Subjects and methods}

We obtained information on alcohol consumption and concern about drinking with a questionnaire containing analogous questions on smoking, exercise, weight reduction, and drinking. ${ }^{78}$ This disguise may increase the detection of excessive drinking in the general population ${ }^{9}$ but was used here because we were interested in the characteristics of the population for another study. The questionnaire was arranged in five parts with a multiple choice format throughout.

The first part of the questionnaire was the simple self assessment question "Do you think you have a drinking problem?" with equivalent questions for smoking, fitness, and weight. Possible responses were no, possibly or probably, and definitely for each. Quantityfrequency scales were used to assess smoking, drinking, and exercise, information being obtained by asking about the average frequency of alcohol consumption per week and the average number of units of alcohol consumed on each occasion. The product of these two values gave an estimate of weekly consumption. The previous week's exercise and drinking were also recorded on a seven day retrospective diary sheet. ${ }^{10}$ Section four comprised the "CAGE" questionnaire for the detection of alcohol abuse." This section was divided into four parts (smoking, exercise, drinking, and weight) with each of the four parts having graded responses as above. In keeping with the criteria for the CAGE interview responders who gave positive responses (not "no") to more than one of the four questions were designated positive.

The final section concentrated on questions related to knowledge of alcohol, all answered on a standard quantity scale. "In your opinion, for a healthy man (woman), what would constitute a reasonable guideline in health education for a safe upper limit of drinking per day (halves/singles)?" We thought that these questions, used in previous studies, would provide useful comparison with findings in those studies on the views of general practitioners and alcohol researchers. ${ }^{2}{ }^{12}$ Finally, we asked, "Have you exceeded the limits you suggest?" (responses: frequently, occasionally, rarely, never) and "Do you think that alcohol has ever affected your academic performance?" (responses as above).

Questionnaires were marked "anonymous and confidential" and made freely available under a plain cover sheet to students on the two main teaching sites at this hospital over two weeks. No distinction was made between those who declined the questionnaire and those who accepted it but failed to complete it. Responses were coded and entered on to computer tables. Results for diary reports are given as means (SE), and as the quantity-frequency calculation yielded estimates rather than precise values only the means are given.

\section{Results}

The questionnaire was freely available to 350 students on two sites; 260 replies were received. We cannot say how many of the remaining 90 students failed to pick up a copy and how many declined to complete it. The numbers of students returning questionnaires, in ascending order of academic year, were $76,58,35,49$, and 40 ; two questionnaires were received from students taking intercalated bachelor of science degrees. The students' image of their drinking was similar between the sexes (table I), half of the sample describing their drinking as moderate.
Correspondence to: Mr Collier 
Table II shows the distribution of drinking as described by quantity-frequency. Although the men drank more than the women, the proportion exceeding the suggested upper limit for each sex was nearly equal. Quantity-frequency estimates gave 31 (23\%) men exceeding 35 units/week and $28(22 \%)$ women exceeding 21 units/ week. The diary reports for the preceding seven days showed $25(19 \%)$ men and $20(16 \%)$ women exceeding the suggested maximum consumptions. Those respondents who described their drinking as heavy $(n=19)$ reported consuming a mean (SE) of 48 (5) units over the preceding week, and the mean of their quantity-frequency estimates also gave a figure of 48 units/week.

The mean alcohol consumption taken from the diary reports was $18.3(2.0)$ units/week for all men in the sample and $11.4(1 \cdot 0)$ for all women. Quantityfrequency estimates were rather higher with reported means of 20.5 units/week for men and 14.6 units/week for women. Both quantity-frequency and retrospective diary measures of consumption were used because the preclinical students surveyed were approaching examinations and we wanted to compare the differences between the two measures as this timing might depress diary reporting but not average quantity-frequency measures.

Overall, the consumption reported for the preceding week tended to fall short of the quantity-frequency averages that students reported. The relation between quantity-frequency estimates and diary reports was studied to compare the closeness of the two measures of consumption in those students approaching examinations and those not. Table III shows the number of respondents whose consumption reported in the retrospective diary was greater than, equal to, or less than the quantity-frequency estimate of average consumption that they gave. The sample of clinical students (123) not engaged in examinations gave diary reports that fell almost equally above and holow their quantityfrequency estimates. In contrast, 72 of the 131 preclinical respondents reported diary consumptions below the quantity-frequency estimates that they gave.

Table II shows the numbers of students who gave positive responses to the CAGE questions and of those reporting any degree of drinking problem, diary

TABLE I-Medical students' description of their drinking habit ${ }^{\star}$

\begin{tabular}{lrcc}
\hline & Men & Women & Total No (\%) \\
\hline None & 9 & 14 & $23(9)$ \\
Little & 41 & 42 & $83(33)$ \\
Moderate & 67 & 58 & $125(50)$ \\
Heavy & 13 & 8 & $21(8)$ \\
\hline Total response & 130 & 122 & $252(100)$ \\
\hline
\end{tabular}

^Eight responders did not describe their drinking.

TABLE II - Some characteristics of student drinkers by quantity-frequency

\begin{tabular}{|c|c|c|c|c|c|}
\hline Units/week & $\begin{array}{l}\text { No (\%) of } \\
\text { students }\end{array}$ & $\begin{array}{l}\text { Mean }(\mathrm{SE}) \text { units } \\
\text { consumed in previous } \\
\text { week from diary }\end{array}$ & $\begin{array}{c}\text { No }(\%) \text { reporting } \\
\text { drinking } \\
\text { problem }\end{array}$ & $\begin{array}{l}\text { No (\%) giving positive } \\
\text { responses to CAGE } \\
\text { questionnaires }\end{array}$ & $\begin{array}{l}\text { No }(\%) \\
\text { academically } \\
\text { affected }\end{array}$ \\
\hline \multicolumn{6}{|c|}{ Men } \\
\hline 0 & $8(6)$ & & & & $2(25)$ \\
\hline $1-$ & $39(29)$ & $5(1)$ & $1(3)$ & $4(10)$ & $14(36)$ \\
\hline $11-$ & $41(31)$ & $19(3)$ & $4(10)$ & $15(37)$ & $28(68)$ \\
\hline $21-$ & $15(11)$ & $29(7)$ & $4(27)$ & $7(47)$ & $9(60)$ \\
\hline $36-$ & $19(14)$ & $30(5)$ & $7(37)$ & $11(58)$ & $12(63)$ \\
\hline$\geqslant 50$ & $12(9)$ & $42(7)$ & $3(25)$ & $11(92)$ & $12(100)$ \\
\hline Total & 134 & $18(2)$ & $19(14)$ & $48(36)$ & $77(57)$ \\
\hline \multicolumn{6}{|c|}{ Women } \\
\hline 0 & $10(8)$ & & $1(10)$ & $1(10)$ & $1(10)$ \\
\hline $1-$ & $62(49)$ & $5(1)$ & $2(3)$ & $7(11)$ & $25(40)$ \\
\hline $11-$ & $26(21)$ & $13(1)$ & $5(19)$ & $10(38)$ & $16(62)$ \\
\hline $21-$ & $13(10)$ & $20(4)$ & $5(38)$ & $9(69)$ & $8(62)$ \\
\hline $36-$ & $7(6)$ & $30(8)$ & $4(57)$ & $4(57)$ & $5(71)$ \\
\hline$\geqslant 50$ & $8(6)$ & $32(8)$ & $4(50)$ & $6(75)$ & $6(75)$ \\
\hline Total & 126 & $11(1)$ & $21(17)$ & $37(29)$ & $61(48)$ \\
\hline
\end{tabular}

TABLE III - Relation between retrospective diary reports of drinking and quantity-frequency category for clinical and preclinical medical students ${ }^{\star}$

\begin{tabular}{lcc}
\hline & $\begin{array}{c}\text { Clinical students } \\
(\mathrm{n}=123)\end{array}$ & $\begin{array}{c}\text { Preclinical students } \\
(\mathrm{n}=131)\end{array}$ \\
\hline Diary > quantity-frequency & 30 & 10 \\
Diary = quantity-frequency & 59 & 49 \\
Diary < quantity-frequency & 34 & 72
\end{tabular}

* Four responders gave incomplete diary or quantity-frequency measures; two students taking intercalated degrees were excluded.

TABLE IV-Limits of alcohol consumption suggested by medical students for health education

\begin{tabular}{lccccccc}
\hline & \multicolumn{7}{c}{ Units/week } \\
\cline { 2 - 7 } & 0 & $1-10$ & $11-20$ & $21-35$ & $36-50$ & $>50$ \\
\hline Suggested by men & 4 & 33 & 62 & 22 & 2 & \\
Suggested by women & 4 & 31 & 52 & 19 & 3 & 3 \\
\hline Total & 8 & 64 & 114 & 41 & 5 & 3 \\
\hline Suggested by men & 6 & 82 & 30 & 8 & 1 & \\
Suggested by women & 5 & 82 & 19 & 8 & 1 & 2 \\
\hline Total & 11 & 164 & 49 & 16 & 2 & 2
\end{tabular}

consumptions, and the numbers admitting to any impairment of academic performance grouped by quantity-frequency category. Forty of the sample reported at least a possible drinking problem, three reporting a definite problem, their week's consumption being 57 units (men) and 63 and 72 units (women). A total of 138 reported that their academic performance had been affected by alcohol at some time; of these, 17 reported being affected frequently. The figure shows the relations between excessive consumption-defined as either a diary report of $>35$ or $>21$ units/week or quantity-frequency averages exceeding these valuesa positive response to the CAGE questions, and at least a possible self assessed drinking problem. A total of 85 respondents gave positive responses to the CAGE questions. Of these, 52 were drinking excessively as defined above.

Table IV shows the estimates of the safe upper limits of drinking for health education given by $93 \%$ of the respondents. More than thalf of those answering (114) gave limits for men higher than for women, 97 gave similar limits for men and women, and only one respondent gave a higher limit for women. These estimates gave average guidelines of about 15 units/ week for men and 9 units/week for women. In fact, 54 of the women $(43 \%)$ exceeded their limit and at least 46 of the men $(34 \%)$ exceeded theirs.

Forty six students described themselves as smokers, the $16(12 \%)$ men and $30(24 \%)$ women $\left(p<0.02, \chi^{2}\right.$ test) having average daily cigarette consumptions of 12 and 11 respectively. The equivalent questions to the CAGE questions such as "Have you ever felt you ought to reduce your smoking?" yielded a positive response in 43 , while 29 admitted to at least the possibility of a smoking problem. Smokers were overrepresented among the heavier drinkers. Women smokers reported a mean consumption of $20.9(3.4)$ units during the previous week $(n=30)$ compared with a mean of $7 \cdot 5$ $(0.8)$ units for their non-smoking counterparts $(n=96$, $\mathrm{p}<0.001$, Student's $t$ test). The 16 male smokers in the study consumed a mean of $27.9(7 \cdot 0)$ units during the week compared with the $17 \cdot 0(1 \cdot 8)$ units of their non-smoking colleagues $(\mathrm{n}=118,0 \cdot 1<\mathrm{p}<0 \cdot 15)$.

\section{Discussion}

Questionnaires on drinking may be used primarily for obtaining data on consumption or, in a clinical 
setting, to screen for problem drinkers. Quantityfrequency estimates and diary reports of drinking suggested that one fifth of the student population drank at a level likely to damage their health. The drinking patterns studied may have been continuous or episodic, but the internal consistency between widely separated parts of the questionnaire and the concordance of the quantity-frequency estimates with diary reports suggested that a consistent pattern of drinking was being studied. These results were obtained from a single medical school, which may or may not vary from the national norm.

Table $\mathrm{V}$ gives a comparison of data with those from other studies, showing figures for both retrospective diary reports and quantity-frequency estimates of average drinking. These two measures of drinking gave similar results, though the diary reports fell below the quantity-frequency estimates, particularly among the heavier drinking women in the sample. As this discrepancy was limited to preclinical students at examination time (table III) we suggest that the quantity-frequency estimates were more reliable.

The male students drank similar amounts to men of a similar age in the general population. The comparison between male students and Goddard and Ikin's sample of 18-24 year olds gave striking and unexpected results. ${ }^{13}$ Female students, however, seemed to drink more than women matched for age in either Goddard and Ikin's study ${ }^{13}$ or that of Breeze. ${ }^{14}$

Compared with the general population in a similar questionnaire study ${ }^{9}$ the medical students showed, overall, a higher positive response rate to CAGE screening for alcohol abuse $(32 \% v 7 \cdot 4 \%)$. This response was also more selective, $61 \%$ of the students compared with $28 \%$ of the general population who responded positively to CAGE screening were drinking excessively. This greater discrimination may reflect greater awareness of the consequences of alcohol abuse. The CAGE questions detected two thirds of the students drinking to excess, the rate of detection increasing sharply with increasing quantity-frequency estimates of consumption. The questions are not ideal as screening for a whole population and are really a clinical tool, but, nevertheless, problems were detected more readily by CAGE screening than by direct questioning. Quantity-frequency estimates may be most suitable for identifying problem drinkers, but also categorise consumption. Diary consumption, problem recognition, positive responses on CAGE screening, and academic disturbance all increased in relation with quantity-frequency category.

TABLE $\mathrm{v}-A$ lcohol consumption by medical students compared with that in studies of other people aged 18 24. Figures are percentages unless stated otherwise

\begin{tabular}{|c|c|c|c|c|}
\hline & \multicolumn{2}{|c|}{ Medical students } & & \multirow[b]{2}{*}{$\begin{array}{c}\text { Breeze } \\
\text { (unmarried) }\end{array}$} \\
\hline & Diary report & $\begin{array}{l}\text { Quantity- } \\
\text { frequency esti }\end{array}$ & Goddard and Ikin ${ }^{13}$ & \\
\hline \multicolumn{5}{|c|}{ Men } \\
\hline & $(n=134)$ & $(n=134)$ & $(\mathrm{n}=293)$ & \\
\hline Non-drinkers & 6 & 6 & 4 & \\
\hline Did not drink in past week & 16 & & 9 & \\
\hline 1-21 Units/week & 45 & 60 & 51 & \\
\hline$>21$ Units/week & 33 & 34 & 37 & \\
\hline$>35$ Units/week & 19 & 23 & 22 & \\
\hline$>50$ Units/week & 9 & 9 & 11 & \\
\hline \multicolumn{5}{|l|}{ Mean consumption among } \\
\hline drinkers (units/week) & $22 \cdot 9$ & & $24 \cdot 6$ & \\
\hline \multirow{2}{*}{ Mean consumption overall (units/week) } & $18 \cdot 3$ & $20 \cdot 5$ & $21 \cdot 4$ & \\
\hline & $\begin{array}{c}\text { Wor } \\
(\mathrm{n}=126)\end{array}$ & $(n=126)$ & $(\mathrm{n}=334)$ & $(\mathrm{n}=259)$ \\
\hline Non-drinkers & 8 & 8 & 6 & 4 \\
\hline Did not drink in past week & 18 & & 17 & 19 \\
\hline 1-21 Units/week & 44 & 60 & 61 & 58 \\
\hline$>21$ Units/week & 30 & 32 & 16 & 19 \\
\hline$>35$ Units/week & 16 & 22 & & 13 \\
\hline$>50$ Units/week & 3 & 12 & 2 & 5 \\
\hline \multicolumn{5}{|l|}{ Mean consumption among } \\
\hline drinkers (units/week) & $14 \cdot 7$ & & $8 \cdot 6$ & $8 \cdot 2$ \\
\hline Mean consumption overall (units/week) & $11 \cdot 4$ & $14 \cdot 6$ & $8 \cdot 0$ & $8 \cdot 1$ \\
\hline
\end{tabular}

The most striking finding was the equality of excessive drinking between the sexes. Twenty three per cent of male students and $22 \%$ of female students drank more than is held to be safe, contrasting with this age group in the general population, in which men drink more, both absolutely and relatively. ${ }^{13} 15$

The equality of alcohol consumption between the sexes was matched by equality of detection of alcohol abuse by CAGE screening at any given consumption. Women directly volunteered a problem more readily than men, as has been shown in the general population. Medical students do seem to be more aware of the dangers of excess alcohol than the general population, as has been shown for smoking. ${ }^{4}$ Despite the prevalence of excessive consumption students provided sensible and even conservative guidelines on upper limits of safe drinking: only eight (3\%) suggested $>35$ units/ week for men and $20(8 \%)$ suggested $>21$ units/week for women. Overall their guidelines were concordant with current guidelines of 14 units/week for women and 21 units/week for men. ${ }^{16}$ They were more consistent with current health education policy than those of general practitioners or alcohol researchers in the past. ${ }^{2}$ The lower recommended consumption for women and the greater concern expressed by women about their drinking may reflect knowledge of the greater dangers inherent in heavy drinking among women.

Populations of medical students are highly selected, and comparisons with people matched for age in the general population are difficult. This age group drinks the most alcohol, ${ }^{13-15}$ and female medical students drink more than women matched for age within the general population. The selected nature of the group may partly explain the results of the questions on smoking. Twice as many female students smoked as male students, which may be largely due to the low rate among men $(12 \%)$ in our sample, which was certainly lower than that in the general population ${ }^{17}$ or professional men. ${ }^{18}$ Smoking among female students differed less from that in the general population but was rather more common than among professional women. ${ }^{18}$

Medical students present an interesting paradox, consuming excessive amounts of alcohol despite having a high awareness of safe limits of drinking. If education on alcohol abuse and its consequences is increasing this picture may represent student knowledge preceding changes in behaviour. This happened with smoking, and if the same pattern is repeated a decline in alcohol consumption may be expected. If, however, awareness and drinking behaviour remain independent more active intervention to reduce drinking and identify problem drinkers may be appropriate.

Female students may be at greater risk as they showed high variance between their awareness of drinking problems and their behaviour. The relation between smoking and drinking suggests that a number of them are compromising their future health despite considerable insight into the dangers of so doing. Informal comments made by students on completing the questionnaire suggested that many had previously been unaware of quite how much they had been drinking. This type of questionnaire may be useful in detecting those people at most risk of damaging their health. Drinking and smoking remain important problems for health care inside, as well as outside, medical schools.

We thank Professor A Clare, Professor N Joels, and Dr M Law for help in preparing this manuscript.

\footnotetext{
Adshead F, Clare A. Doctors' double standards on alcohol. Br Med f 1986:293:1590-1

Wallace P, Cremona A, Anderson P. Safe limits of drinking: general practitioners' views. Br Med f 1985;290:1873-6.

Barrison I, Viola L, Lvon IM. Do housemen take an adequate drinking history? Br Med f 1 1980;281:1040.
} 
Plant M. Drugs in perspective. London: Hodder and Stoughton, 1987

5 Murry R. The medical profession. In: Plant M, Hore B, eds. Alcohol problems in employment. London: Croom Helm, 1980

6 Paget J. What becomes of medical students? Saint Bartholomew's Hospital Reports $1869 ; 5: 238-42$.

7 Wallace $\mathrm{P}$, Haines A. General practitioner and health promotion. Br Med $\mathcal{F}$ 1984;289:534-6.

8 Wallace $\mathrm{P}$, Haines $\mathrm{A}$. Use of a questionnaire in general practice to increase the recognition of patients with excessive alcohol consumption. $\mathrm{Br}$. Med $\mathrm{f}$ 1985;290:1949-53.

9 Wallace P, Brennan P, Haines A. Drinking patterns in general practice patients. F R Coll Gen Pract 1987;37:354-7.

10 Anonymous. That's the limit. London: Health Education Authority, 1988:5.

11 Mayfield D, McLeod G, Hall P. The CAGE questionnaire: validation of a new screening instrument. Am $\mathcal{P}$ Psychiatry 1974;131:1121-3.
2 Anderson P, Cremona A, Wallace P. What are safe levels of alcoho consumption? BrMed f 1984;289:1657-8

13 Goddard I, Ikin C. Drinking in England and Wales in 1987. London: HMSO, 1988.

14 Breeze E. Women and drinking. London: HMSO, 1985.

15 Office of Population Censuses and Surveys. General household survey 1984 London: HMSO, 1986.

16 Royal College of Physicians. A great and growing evil. London: Tavistock, 1987.

17 Wald N, Kiryluk S, Darby S, Doll R, Pike M, Peto R. United Kingdom smokin statistics. Oxford: Oxford University Press, 1987.

18 Office of Population Censuses and Surveys. Cigarette smoking 1972 to 1986. OPCS monitor 1988; 1 (SS88/1.)

licipted 12 April 1989$)$
Department of Human Molecular Genetics, Central Institute of Molecular Biology, Academy of Sciences of the German Democratic Republic, 1115 Berlin-Buch, German Democratic Republic Charles Coutelle, MD, professor of human molecular genetics

\section{Department of}

Biochemistry and

Molecular Genetics and North West Thames

Regional DNA Laboratory, St Mary's Hospital Medical School, London W2 1PG

Carolyn Williams, BSC, senior biochemist

Robert Williamson, PHD, professor of biochemistry

Institute of Obstetrics and Gynaecology, Royal Postgraduate Medical School, London W12 0HS Alan Handyside, PHD, senior lecturer

Kate Hardy, MA, research assistant

Robert Winston, FRCOG, professor of fertility studies

Correspondence to: Professor R Williamson, St Mary's Hospital Medical School, London W2 1PG.

\title{
Genetic analysis of DNA from single human oocytes: a model for preimplantation diagnosis of cystic fibrosis
}

\author{
Charles Coutelle, Carolyn Williams, Alan Handyside, Kate Hardy, Robert Winston, \\ Robert Williamson
}

\begin{abstract}
Gene sequences in human oocytes were studied to investigate the possibility of diagnosing inherited or sporadic genetic disease before implantation after in vitro fertilisation. By specific amplification the possibility of analysing the DNA from single human oocytes for a specific gene was shown, and genotypes for markers closely linked to cystic fibrosis and Duchenne muscular dystrophy were determined. Single oocytes were used to approvimate the total amount of DNA present in a single cell taken for biopsy from a 4-16 cell blastocyst. With a new technique for specific DNA amplification, the polymerase chain reaction, these data can be obtained within several hours of cell isolation. Extreme care must be taken to avoid any contamination of the sample with DNA from other sources.

With this technique genotyping for single gene disorders is feasible with an accuracy and on a time scale that would allow implantation of the zygote after in vitro fertilisation without freezing.
\end{abstract}

\section{Introduction}

Prenatal diagnosis of genetic abnormalities by analysing DNA can now be offered for inherited diseases that are caused by a known gene defect, provided that DNA probes are available to identify the mutated gene or detect a restriction fragment length polymorphism closely linked to the affected locus. ${ }^{1}$ New techniques that use luteinising hormone releasing hormone agonists to obtain large numbers of oocytes, progress in techniques of in vitro fertilisation, and the successful development of fertilised embryos in vitro to healthy children have led to requests for diagnosis from DNA before implantation of the fertilised egg from families known to be at risk for genetic disease. ${ }^{3+}$ This is possible for repetitive DNA sequences, such as those on the Y chromosome that permit sex testing before implantation..$^{5}$ In this study we show that similar analysis will be possible for single genes, such as the cystic fibrosis gene.

There is a particular demand for such diagnostic facilities from women who were sterilised after the birth of an affected child but who now wish to have more children. Such a diagnosis would have to be made on a single blastomere or on only a very few embryonic cells taken at an early stage of development, and preferably be quick enough to allow the pre-embryo to be transferred without cryopreservation. Until recently the sensitivity of detecting single copy sequences in the human genome was not sufficient to permit gene analysis with DNA from a single cell, but now the polymerase chain reaction can be used to amplify specific DNA sequences. ${ }^{5-7}$

Two common inherited diseases are cystic fibrosis and Duchenne muscular dystrophy. We used gene amplification with oligonucleotide primers specific for a part of the coding sequence of dystrophin, which when mutated causes Duchenne muscular dystrophy, and with primers identifying the locus CS.7, which maps close to the mutation that causes cystic fibrosis.

\section{Materials and methods}

DNA was obtained from oocytes collected from women undergoing in vitro fertilisation ${ }^{8}$; the oocytes studied had failed to fertilise after insemination. Unfertilised oocytes were used because they are similar to single blastomeres cytologically, contain only the maternal genome, and are diploid. Contamination with adherent cumulus cells or spermatozoa was avoided by removing the zonae pellucidae. Each oocyte was examined for evidence of the first polar body, which in most cases was lost when the oocytes were pipetted. Each oocyte was transferred into a screwcapped siliconised Eppendorf tube and boiled with $20 \mu \mathrm{l}$ water for five minutes before the polymerase chain reaction cocktail was added.

Polymerase chain reaction entails enzymatic copying of DNA using a series of repeated cycles, in each of which the DNA between two oligonucleotide primers is synthesised, so as to give logarithmic amplification of the gene sequence under study. ${ }^{5-7}$ The amplification of DNA was performed in $100 \mu \mathrm{l}$ assay volumes, each containing $1 \cdot 5-2 \cdot 0$ units of Taq DNA polymerase (Cetus/Perkin-Elmer) as outlined in the manufacturer's recommendations. ${ }^{6}$ The $\mathrm{mix}$ contained $50 \mathrm{mM}$ potassium chloride, $10 \mathrm{mM}$ TRIS-chloride at $\mathrm{pH} 8 \cdot 3$, $1.5 \mathrm{mM}$ magnesium chloride, $0.01 \%$ (wt/vol) gelatin, and $200 \mu \mathrm{M}$ of each deoxynucleotide triphosphate.

To analyse the gene for Duchenne muscular dystrophy we used 50 pmol of the oligonucleotide primers of 20 bases $5^{\prime}$-GAAATTGATCGGGAATTGCA-3' and 5'-AATTTGTGCAAAGTTGAGTC-3' bordering a 183 base pair exon of the dystrophin gene locus (nucleotides 5948 to 6130 ). ${ }^{9}$ To analyse the gene for cystic fibrosis we used the oligonucleotide primers of

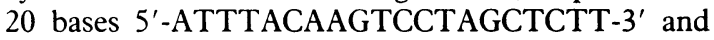
5'-AAATGATGGCAAGAGATGTC-3' bordering a 324 base pair sequence containing the polymorphic Hhal restriction site in linkage disequilibrium with cystic fibrosis. ${ }^{10}$ In all experiments that used less than $500 \mathrm{ng}$ of DNA template, and for all oocyte 